\title{
A CASA, O LAR E O MOBILIÁRIO
}

Ana Claudia Maynardes

Universidade de Brasília

anacmay@gmail.com

Resumo: Este artigo faz uma análise acerca das inter-relações da formação do espaço doméstico, enquanto influenciador do modo de morar, com a evolução do uso e da produção do mobiliário. Por questões metodológicas, apresentamos fatos pontuais, considerados relevantes, que ocorreram em algumas sociedades do continente europeu e norte americano para o entendimento de nossa abordagem. Também destacamos períodos em que os móveis, ora eram utilizados como objetos de função puramente utilitária, ora, quando a eles, eram agregadas funções de dimensões simbólicas. Atualmente, a casa está aberta ao mundo, um local onde o trabalho, a informação e a ciência adentram em todas as dimensões. As tecnologias penetraram a habitação: desmaterializaram suas paredes, sua estabilidade e os seus limites.

Palavras-chave: design de mobiliário; casa; lar

\begin{abstract}
This article is an analysis of the interrelations of the formation of the domestic space, while influencing the way of living, with the evolution of the use and production of furniture. For methodological reasons, we present specific facts deemed relevant, that have occurred in some societies of European and North American continent to the understanding of our approach. We also highlight periods when the furniture, sometimes were used as purely utilitarian function objects, sometimes, when they, symbolic dimensions functions were aggregated. Currently, the house is open to the world, a place where the work, information and science they enter in all dimensions. Technologies entered the room: dematerialized its walls, its stability and its limits.
\end{abstract}

Keywords: furniture design; house; home 


\section{INTRODUÇÃO}

Os móveis, enquanto participantes do contexto da habitação, assim como outros objetos utilitários, sempre foram parte integrante e suporte das transformações que aconteceram na interioridade doméstica e privada e, como objetos produzidos pelo homem, representaram e ainda representam o modo de pensar e agir do indivíduo e da sociedade, bem como seu estágio tecnológico.

À medida que as condições da vida doméstica começaram a mudar, há um maior desejo de privacidade, o que refletiu no ambiente interno. A partir dessas mudanças os móveis assumem outras características e passam a ser mais adaptados aos padrões requeridos e começam a não mais serem vistos como aqueles de caráter apenas utilitário. À medida que a vida se tornava mais íntima e social, os móveis vão aumentando em número e diversificação e sua relação com o indivíduo ia se tornando mais particularizada.

Conforme as estruturas familiares iam tomando outras dimensões, surgia também o conceito de intimidade e privacidade e, aos móveis, iam surgindo características peculiares e diferenciados a cada situação, como expressão de personalidade.

A habitação e os objetos que fazem parte de sua paisagem atravessam um momento determinante no que diz respeito à relação entre a casa e o seu habitante. Não se tem mais o local fictício, revelado como abrigo, conforto e bem-estar, e que foi sinônimo de lazer e privacidade como no século XIX. Atualmente, a casa está aberta ao mundo, um local onde o trabalho, a informação e a ciência adentram em todas as dimensões. As tecnologias penetraram a habitação: desmaterializaram suas paredes, sua estabilidade e os seus limites.

Este artigo tem o objetivo de fazer uma breve análise de como a configuração do lar e da casa vai se formatando conforme as condições sociais, culturais, tecnológicas e ideológicas vão se configurando, bem como abordar o seu mobiliário.

\section{DESENVOLVIMENTO}

A França e Inglaterra sempre foram palco de situações que contribuíram imensamente para evidenciar a evolução dos interiores domésticos.

A aristocracia francesa formava uma sociedade essencialmente urbana. Perrot (2009) nos conta que a casa como conhecemos hoje, num sistema de tripartição ${ }^{1}$ advém desse período. A burguesia parisiense emergente, ávida por se "igualar" à aristocracia, copiava seus luxuosos estilos de habitação. Para receber a fina sociedade em seu seio familiar em suntuosas festas era necessário um ambiente - sala de estar amplo e confortável. Para conservar a intimidade e privacidade (cada vez mais significativas) dos membros da família, havia os quartos. Já para os numerosos empregados necessários para os afazeres domésticos, existia uma área de serviço. Assim, dividir a residência em área social, área íntima e área de serviço, foi se consolidando como um modo sofisticado de viver.

Aos ambientes considerados sociais, destinava-se uma dimensão coletiva e pública: tanto para o relacionamento familiar, quanto para recepção de convidados; ou por estarem, em sua maioria, localizados em áreas voltadas para a rua,

\footnotetext{
${ }^{1}$ Este sistema se refere àquele em que a configuração espacial da casa é dividida em três partes: área social, área íntima e área de serviço.
} 
considerados então, como espaços que estão entre o privado (a casa) e o público (a rua).

Além das dimensões pública e coletiva, essa área deveria produzir um valor de status social; funcionar como um lugar onde a burguesia pudesse ostentar uma imagem como de sua própria família. Por isso, usavam rica decoração e mobílias ornamentadas; tudo compondo para uma cenografia das salas.

À área íntima, diferentemente da social, destinam-se os quartos, considerados locais da vida privada da família. São nesses cômodos que a identidade do indivíduo ascende, deixando de lado a identidade familiar. O quarto, então, se constitui como um espaço reservado à intimidade, o espaço mais privado da casa.

[...] se entrarmos num quarto burguês dos anos oitenta [1880], apesar de todo aconchego que ele irradia, talvez a impressão mais forte que ele produz se exprima nessa frase: Não temos nada a fazer ali porque não há nesse espaço um único ponto em que seu habitante não tivesse deixado seus vestígios. Esses vestígios são bibelôs sobre prateleiras, as franjas ao pé das poltronas, as cortinas transparentes atrás das janelas. O guarda-fogo diante da lareira. (BENJAMIN,1994, p. 117-118)

A outra situação é apontada por Forty (2007). O conceito de lar sofreu grande influência quando do início da industrialização. Na Idade Média a casa era um local que incorporava o trabalho às atividades habituais de morar, dormir e comer. Quando o trabalho produtivo foi removido para as fábricas, o lar tornou-se um lugar unicamente para dormir, comer, criar filhos e principalmente para desfrutar o lazer.

Para tanto, a fábrica e o escritório viraram sinônimos de local de opressão à classe trabalhadora e o lar transformou-se em um abrigo onde as pessoas buscavam um pouco de respeito por si mesmas. Essa situação levou as pessoas a separarem os dois espaços, não só fisicamente, mas também emocionalmente. Assim, o lar passou a ser considerado um repositório das virtudes perdidas ou negadas no mundo exterior, e essa representação tinha o objetivo de "[...] transformar o lar em um lugar de ficção, um lugar onde florescia a ilusão" (FORTY, 2007, p. 140). Às mulheres cabia a tarefa de preservar o aspecto sacrossanto da casa. Os vitorianos adotaram várias estratégias de comportamento para satisfazer essas ilusões; uma delas foi o desenvolvimento de padrões especiais de gosto e design para o lar. Na escolha da mobília ou na harmonia das cores, o ambiente tinha de eliminar todas as associações com o trabalho.

Nesse sentido, o lar transformou-se em um lugar que estimulasse a dissociação total entre o mundo interior e o mundo exterior.

O ambiente em que se vive se contrapõe pela primeira vez, para o homem privado, ao lugar do trabalho. O primeiro se constitui no interior, o escritório é o seu complemento. O homem privado, realista no escritório, exige do interior que o mantenha em suas ilusões. Esta necessidade é tanto mais estimulante quando nem pensa em estender suas reflexões mercantis às sociais. Reprime ambas ao configurar seu entorno privado. E assim resultam as fantasmagorias do interior. Para o homem privado o interior representa o universo. Reúne nele o longínquo e o passado. Sua sala é a platéia no teatro do mundo (BENJAMIN, 1973, p. 167-168).

O conceito de lar como conhecemos hoje, não se dá apenas a partir da incorporação da domesticidade e do binômio público x privado, mas também como 
resultado da revolução industrial. A partir do momento em que as pessoas deixaram de realizar suas obrigações profissionais dentro de suas residências e passaram a trabalhar em fábricas, escritórios e lojas, a casa adquire um novo e diferenciado patamar na vida das pessoas, e isso foi refletido diretamente em sua decoração, por conseguinte, na conformação dos móveis.

A exigência básica dos novos lares era que se deveria eliminar toda e qualquer associação com o trabalho. Segundo Garret (apud FORTY, 2007, p. 141) a sala de visita moderna começou a exibir com certa frequência um estilo "espalhafatoso e teatral" na decoração e mobiliário. Essa representação do lar deu-lhe um status de ficção e ilusão que deveria, inclusive, eliminar os "maus sentimentos". Para tanto, os móveis residenciais começaram a ficar coloridos, macios e aveludados.

[...] a partir do louvável desejo de excluir todos os pensamentos e objetos do dia de trabalho, a sala de visita moderna exibe com demasia freqüência um estilo espalhafatoso e teatral de decoração e mobiliário [...] (GARRET, 1879, p. 56 apud FORTY, 2007, p. 141)

Os burgueses ingleses passavam a maior parte do tempo em casa, visitando-se mutuamente, jogando e bordando. Essas atividades transcorriam em torno da casa, e assim a moradia adquiriu uma importância social jamais vista, antes ou depois. A residência era um lugar social, mas com privacidade.

Durante todo o século XIX a "beleza" foi o principal requisito a ser adotado como meio para que o lar atingisse o seu lugar de santidade. No conceito de beleza, além de conforto e satisfação dos sentidos estéticos, havia a significativa representação das virtudes morais da verdade e da honestidade. Às mulheres, mais uma vez, cabia a responsabilidade pela busca da beleza, por seus efeitos morais sobre os outros membros da casa.

Buscou-se então a "mobília de arte", conceito que surgiu devido ao fato de que não se achavam no comércio móveis que satisfizessem os padrões estéticos e morais de beleza, como, por exemplo, honestidade moral e honestidade das formas e dos materiais. O objetivo do mobiliário com arte era o de reduzir a quantidade de móveis e criar mais espaço nas salas e quartos.

Os móveis pesadamente estofados foram deixados de lado, em favor de cadeiras de estrutura de madeira e canapés com almofadas soltas. Móveis escuros, dourados e cores como escarlate foram banidos em favor de tons pastéis e trabalhos de marcenaria pintados de branco. Tapetes sobre assoalhos de madeira ou tacos eram preferíveis a carpetes. Em todas as dependências, buscava-se um ar de informalidade e não se estimulavam as simetrias no mobiliário. Por fim, o mais importante de tudo: imitações e tapeações estavam proibidas. Mobília que disfarçasse o modo como fora feita, ou seus materiais, era considerada desonesta e, portanto, deveria ser evitada. (FORTY, 2007, p. 154) 


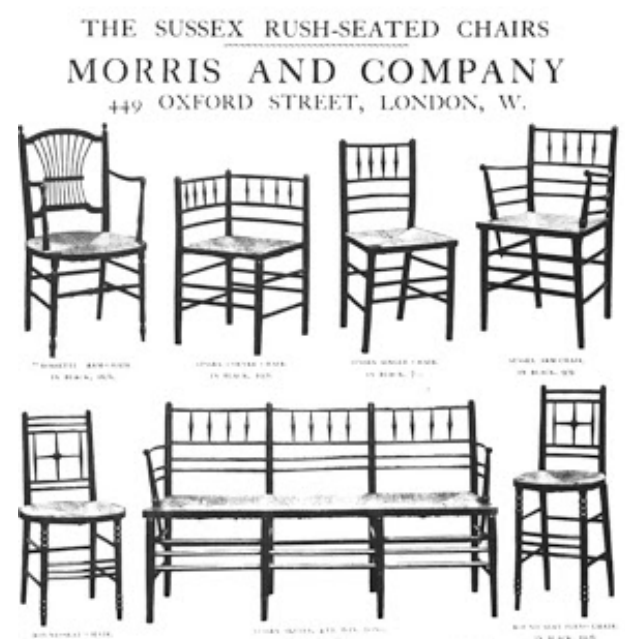

Figura 1 - Catálogo dos móveis Morris \& Company, Móveis fabricados por Willian Morris Fonte: www.furnitestyles.net

A figura 1 retrata as famosas cadeiras fabricadas por Willian Morris no século XIX. Essas peças eram projetadas e produzidas segundo os novos preceitos de "honestidade", em que fora banido todo e qualquer elemento decorativo que pudesse demonstrar imitação ou camuflagem. Os ornamentos eram restritos à aplicação de delicada marchetaria. Vale ressaltar que nesse período o processo de industrialização no setor moveleiro já estava totalmente disseminado, e novas técnicas estavam sendo criadas, como por exemplo, a que curvava peças em madeira sob pressão térmica.

Outro aspecto extremamente importante que se deve destacar é a questão da limpeza e higienização. Ainda que a limpeza tenha um viés significativamente relevante - sua relação científica com a saúde ${ }^{2}$-, esse não foi o único significado. Forty (2007, p. 217) explica que enquanto categorias neste contexto, limpeza e sujeira são subjetivas: o conceito que estava por trás era o de "impor ordem ao mundo". Esse autor faz uma relação com o temor burguês de perder o poder e a autoridade social e política, não lhe parecendo implausível que um "regime de limpeza e ordem" fosse adotado pela classe média como reação à convulsão social e para lhe inspirar alguma segurança psicológica contra ela.

A partir da última década do século XIX, tanto na Europa quanto na América surgiram estratégias de saúde pública que partiram de profissionais liberais e reformistas sociais. A atenção foi dispensada a vários setores da vida cotidiana: do vestuário à poeira doméstica; da alimentação das crianças ao alcoolismo. Lar, lojas, escolas, edifícios públicos, vagões de trem, tudo recebeu uma atenção cuidadosa. ${ }^{3}$

Para Forty (2007, p. 299-230), a questão da limpeza e higiene foi colocada como uma questão de apelo emocional: "O menor desvio da limpeza perfeita era

\footnotetext{
2 Junto à teoria miasmática, que considerava a ventilação dos ambientes uma profilaxia eficiente, em 1860 Louis Pasteur e Joseph Lister haviam estabelecido a base para uma teoria microbiana. A atenção foi então dada a tudo que pudesse carregar germes, e isso, além de moscas, ratos e baratas, incluía objetos, vestuário e os equipamentos domésticos.

${ }^{3}$ Surgiram então escolas que ensinavam as meninas sobre o serviço doméstico, bem como as preparavam para o casamento. Na grade de disciplinas estavam técnicas de limpeza (como tirar pó e limpar o chão), explicações sobre técnicas nutricionais para uma boa alimentação e acerca das causas das doenças.
} 
causa de ansiedade social, pois a passagem invisível dos germes podia pôr em risco a saúde da família, dos companheiros e até de toda a nação".

Essa postura obviamente foi instaurada no design dos objetos. Na mobília, isso influenciou sobremaneira na forma e na substituição dos materiais retentores de pó, como tecidos rugosos, veludos, formas entalhadas e com muitos detalhes, por materiais de superfície lisa, linóleo, encerado ou couro. A tecnologia do ferro fundido ou em barras também foi um passo à frente.

No final do século XIX grande parte da mobília já incorporava traços "higiênicos" de limpeza formal: mínimo de relevo ornamental e formas mais geométricas e menos "rebuscadas". A relação entre indivíduo e objeto era baseada na ação simbólica voltada para duas vertentes: uma levava à questão de ordem e organização; a outra incluía os avanços do desenvolvimento industrial e, consequentemente, suas tecnologias e processos.

Há de se considerar também a não menos relevante questão do surgimento do movimento Art Nouveau. Vários autores, como Pevsner (1994), Argan (1992a) e Bomfim (1998), o colocam como símbolo de identificação enquanto classe social (aristocracia e burguesia) e reação ao estilo racional da indústria. O Art Nouveau surgiu como um ornamento expressivo da era industrial. Paradoxalmente ao contexto da influência da higienização, as formas assimétricas, de motivos ornamentais, formas orgânicas inspiradas na natureza do estilo, denotavam uma estetização da vida, superando a linguagem fria e racional não só da industrialização como também do conceito ideológico de vida racional, já disseminado na sociedade. Foi uma tentativa de inserir uma segunda natureza à rudeza industrial: "O estilo floral do Art Nouveau gostaria de revesti-la [a cidade e os objetos] com sua ornamentação alastrante como uma trepadeira, convertê-la numa segunda natureza" (ARGAN, 1992b, p. 189).

Segundo Bomfim (1998), apesar de suas características peculiares, tanto o movimento Arts and Crafts quanto o Art Nouveau possuem semelhanças. A primeira é que os dois propuseram produtos baseados na produção artesanal e industrial como meio de melhorar a qualidade estética dos produtos. A segunda é que ambos encontraram seus fundamentos na tradição: o Arts and Crafts lutou contra o historicismo e pregou o retorno à ordem da Idade Média; o Art Nouveau, engajado com a burguesia, buscou no humanismo da Renascença sua fundamentação. Foram movimentos que se inspiraram no passado e não poderiam apresentar uma solução ao problema colocado pela estética industrial que, por sua vez, buscava soluções formais junto ao novo contexto da produção industrial.

$O$ século $X X$ trouxe várias situações que definiram o modo de viver da sociedade. Uma delas foi que o conforto, considerado uma condição que antes era privilégio de apenas uma pequena parte da população, se difunde com a industrialização e a democratização da produção em massa. Grande parcela da população passou a ter em suas casas equipamentos e aparelhos que facilitavam o serviço doméstico e que melhoravam as condições de aquecimento e iluminação.

Nessa etapa da história a posição que a mulher assume perante a sociedade, à família e a casa tem relação direta com o indivíduo e sua residência, com os móveis e objetos e a configuração do espaço interno. No período das guerras na Europa, as donas de casa foram impelidas a trabalhar nas lojas e escritórios do mundo industrial, substituindo os homens que haviam ido para a guerra. As carentes foram movidas pela necessidade financeira, as de classe média e as de famílias mais abastadas exigiam seu 
direito de trabalhar fora como o homem. Os diversos aparelhos para o lazer ou para facilitar o serviço doméstico, como eletrodomésticos, televisão e rádio, tornaram-se imprescindíveis. Com a incorporação desses aparelhos nas despesas familiares, o salário da mulher tornou-se indispensável. ${ }^{4}$

Rybczynski (1999) salienta que as condições de conforto de quem realizava as tarefas domésticas foram amenizadas a partir da inserção dos aparelhos eletrodomésticos, pois proporcionavam a realização das atividades com menor esforço. No início do século XX a mulher norte-americana fazia a maior parte do serviço doméstico, pois além de haver tecnologia acessível elas tinham renda para adquiri-los.

Boyle (1993) observa que na Inglaterra os empregados domésticos migraram para outro tipo de trabalho, devido ao aumento da oferta de empregos nos escritórios e nas indústrias. As casas tornaram-se menores, mais práticas e com menos móveis. As tarefas diárias eram mantidas pelas próprias donas da casa, auxiliadas por eletrodomésticos que permitiam economia de mão de obra e redução do serviço. "[...] cunhou-se uma nova expressão para descrevê-los: 'labor saving appliances' (aparelhos de redução de trabalho)", (RYBCZYNSKI, 1999, p. 89).

Por volta de 1910, nos Estados Unidos, o serviço doméstico foi posto no centro da vida da mulher de classe média ${ }^{5}$. A cozinha foi o lugar da casa que mais passou por alterações significativas nesse período:

[...] do forno de ferro fundido e dos fogões a gás e elétrico, maior diversidade de panelas e recipientes, provocaram um aumento e a separação da cozinha. Que gradualmente passou a rivalizar com a sala de estar enquanto ponto focal da vida familiar: agora ela já não ficava no porão como antigamente, mas no andar térreo, perto da sala de jantar. Seu projeto passou a ser cuidadosamente ponderado e suas paredes foram revestidas com papel lavável; as mesas tiveram a altura cuidadosamente planejada para oferecer as condições de trabalho mais propícias. (BOYLE, 1993, p. 159)

A partir dessas condições é que surgiram os primeiros conceitos de cozinha planejada como ilustrado na figura 2. Armários multifuncionais: fáceis de montar, de manipular, de limpar; enfim, fáceis de usar. Muitos materiais, naturais ou artificiais, como laminados plásticos ou de madeira natural, foram desenvolvidos pela indústria como opção de acabamento para a superfície de trabalho, já que proporcionavam maior higiene, durabilidade e facilidade de limpeza.

De arquitetos modernos e exposições de artes decorativas à indústria que produzia produtos inovadores para a casa, todos os esforços estavam voltados a tornar

\footnotetext{
${ }^{4}$ Rybczynski (1999) assegura que era necessário algum tipo de energia para fazer funcionar as tecnologias que iam acontecendo na atividade industrial para dentro da residência. $O$ gás foi a primeira fonte de energia artificial inserida na casa, seguido pela eletricidade e pelo gerador elétrico, depois pelo aquecedor com resistência e pela lâmpada incandescente. Com a eletricidade dentro das casas, apesar de seu largo uso ocorrer primeiramente na iluminação, ela poderia ser utilizada como fonte de energia para outras funções.

${ }^{5}$ As americanas Christine Frederick e Lillian Gilbreth, que ficaram conhecidas como engenheiras domésticas, difundiram a idéia da casa eficiente. Foram criados cursos de economia doméstica e o trabalho doméstico foi redefinido como uma ciência exata. As técnicas do estudo do tempo, desenvolvidas para o trabalho na indústria, foram aplicadas pelas engenheiras a fim de racionalizar o trabalho da casa.
} 
o domicílio um local mais "funcional" e independente das questões de ordem decorativa atreladas aos estilos históricos. É nessa época também que se instaura o american way of life, que tinha o objetivo de divulgar o estilo de vida norte-americano, e junto com ele seus produtos industrializados. A mais nova (e talvez a mais importante) atração do lazer doméstico, a televisão, instalou-se definitivamente em posição de destaque nas salas de estar. Surgiram então móveis que não apenas servissem de apoio, mas convertessem a televisão num objeto de destaque.

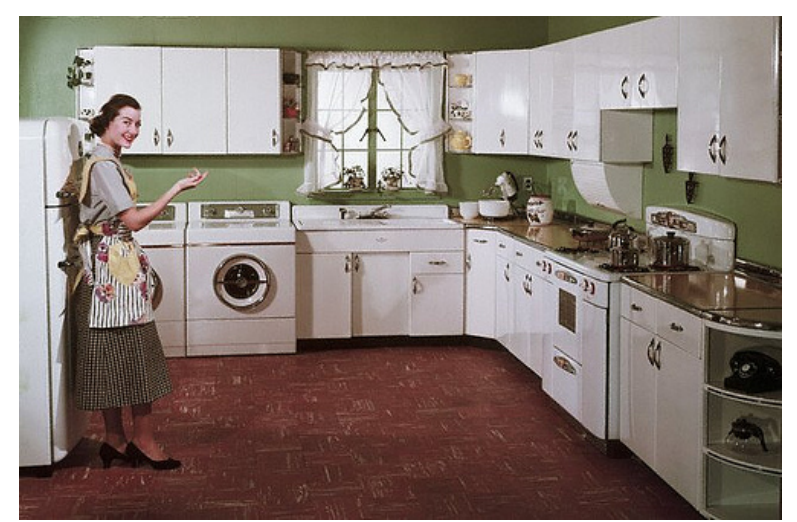

Figura 2 - Cozinha no estilo american way of life Fonte: http://www.belvederellc.com/kitchenbaths

A constituição do ambiente doméstico e do conforto foi gradual, e as mudanças mais significativas em relação à residência ficaram restritas ao espaço interno. Contudo, no início do século XX, paralelamente aos avanços tecnológicos ligados ao desenvolvimento do conforto humano na residência, uma revolução estética que envolvia a relação direta do ambiente interno e externo estava a caminho.

A sociedade europeia buscava um estilo original e novo, de acordo com os novos tempos e ante o progresso técnico. A influência do historicismo, do ecletismo e do excesso de ornamentações começou a encontrar intensa aversão. ${ }^{6}$

Com a expansão do comércio internacional a Europa passou por um período de prosperidade econômica até a 1a Guerra Mundial, período conhecido como Belle Époque. Entre outros fatores, este abriu campo para experiências artísticas de vanguarda que procuravam um estilo "inédito" e sem influências dos anteriores. Haveria de se criar uma nova possibilidade de linguagem para a criação e desenvolvimento de projetos: não era mais possível projetar baseado em estilos passados. Movimentos estéticos e artísticos como o Art Nouveau, De Stijl, o Futurismo e o Cubismo foram base para o movimento moderno.

Aquilo que pudesse representar o passado foi retirado. Rybczynski (1999) aduz que o modernismo é um modo brando de esnobar aquilo que pudesse parecer familiar.

Um prédio moderno era uma experiência total; não só a disposição interna, mas também os materiais de acabamento, a decoração, os acessórios e a localização das cadeiras eram planejados. O que resultou em cômodos de

${ }^{6}$ Consultar Bayeux (1997), Argan (1992a) e Pevsner (1994). 
uma consistência visual que não era vista desde o rococó [...] Os interiores mais admirados eram aqueles onde tudo havia sido projetado por um só arquiteto - inclusive a iluminação, as maçanetas e os cinzeiros. E é claro, os móveis, especialmente os móveis. (RYBCZYNSKI, 1999, p. 103)

O foco à originalidade e a insistência pelo novo fazem que o projetar esteja totalmente voltado às formas de produção industrializada e na utilização de novos materiais. Assim, o movimento moderno provoca uma ruptura total com o passado e com aquilo que fundou, aprimorou e desenvolveu o móvel e a configuração do espaço interior até então. A arquitetura moderna para residência não foi aceita imediatamente, igualmente os seus móveis.

Os arquitetos modernos eram também adeptos do ideário socializante de William Morris, mas não acreditavam no poder da construção de uma estética como totalidade da atividade humana, cognitiva e afetiva sem apelar para a indústria. $O$ ideal de seus pensamentos era a tônica na arquitetura da cidade, "mas da cidade do trabalho, não a cidade-refúgio do privilégio" (Katinsky, 1999, p. 36).

Sem dúvida, a arquitetura e o design modernos demonstraram a sua intenção de transformar a sociedade a partir da habitação e de seus objetos. Contudo, na maioria de seus exemplos, embora de raiz inovadora como nunca visto antes, não conseguiram atingir os seus objetivos inteiramente, pois o indivíduo a que se propunham ainda se encontrava despreparado para recebê-los. Introduziram o racionalismo, as novas formas de distribuição funcional e os princípios higienistas, bem como estabeleceram a repetição e a simetria. É sensato afirmar que a arquitetura e o design modernistas discutiram profundamente os modos de habitar e usar os objetos a partir de propostas experimentais estandardizadas.

A criação do "modelo standard" deu origem a objetos extremamente estáticos que possuíam uma mesma sintaxe, em que a individualidade e a diversidade do indivíduo se viram interrompidas pelo padrão. Como resultado, a consequente perda de identidade da casa e do sujeito.

Se por um lado, os objetos pautados por princípios modulares produzidos industrialmente em série tinham a competência de resolver os problemas com relação à rapidez e à economia produtiva, por outro conferiram um modo de vida também estandardizado ao indivíduo e à sociedade.

Tanto para o entendimento do processo produtivo e seus sistemas, para o desenvolvimento de processos e métodos de projeto, quanto para a formatação do design enquanto profissão trata-se de um passado próximo importante. Apesar de ter chegado a um estado de ruptura com o tradicional, foi um período intensamente prolífero que proporcionou ao design um desenvolvimento e autonomia sem precedentes. $O$ grande questionamento que se faz é que essa proposição virou dogma, não permitindo espaço para reflexão.

Atualmente fala-se sobre as transformações e mudanças que estão ocorrendo nos conceitos de casa e de lar. Contudo, em sua essência, estes conceitos são ainda pouco dados a mudanças: a casa sempre foi o lugar do indivíduo, onde este encontra abrigo, bem-estar e conforto. Os conceitos de estabilidade, permanência e continuidade ainda estão presentes e é na casa e por meio de seus objetos que o indivíduo constrói o seu mundo de referências, a sua vida.

É certo também que as necessidades básicas inerentes ao ser humano se encontram decisivamente à mercê de condicionantes culturais e locais que tornam 
indispensável e essencial uma redefinição da função, da forma e da estética que envolve a casa e seus objetos, assim como, de sua dimensão simbólica.

A complexidade, a mutabilidade e a indeterminação da vida do sujeito contemporâneo constituem fatores decisivos para um novo pensar do interior doméstico, estabelecendo um cenário que melhor se adapte ao seu estilo de vida. $A$ permanência, a previsibilidade e a rigidez, que caracterizaram o projeto moderno estão sendo substituídas por mecanismos abertos, em que a ideia de sistema ${ }^{7}$ é uma das grandes correntes.

A habitação, assim como os objetos que compõem seu cenário, atravessa um momento determinante no que diz respeito à relação entre a casa e o seu habitante. Ela já não é mais um local idílico, manifestado como abrigo, conforto e bem-estar, e que foi sinônimo de lazer e privacidade, como na casa burguesa do século XIX até bem pouco tempo. Atualmente, ela está aberta ao mundo, um local onde o trabalho, a informação, a (inter) comunicação e a ciência penetram em sua esfera. As tecnologias adentram a habitação, desmaterializando as suas paredes, a sua estabilidade e os seus limites. Para além do seu caráter mítico de proteção como citado em Homero, a casa hoje é um espaço simbólico em ativa inconstância.

A evolução e inserção da tecnologia na vida cotidiana e as transformações da sociedade complexa a que assistimos hoje são consideradas as grandes responsáveis pelas alterações do espaço habitacional contemporâneo. Conceitos como família, imobilidade, privacidade e intimidade estão sendo colocados à prova.

A casa encontra-se imersa num mundo tecnológico que desmaterializou os seus limites e consequentemente interferiu nos conceitos pré-estabelecidos. 0 computador, o aparelho celular, o ipod, o ipad, os sistemas home theater e tantos outros aparelhos eletrônicos que trazem tanto o trabalho, como o mundo exterior para dentro da casa, emergem e reinterpretam as características do espaço habitacional, dos equipamentos e utensílios domésticos, assim como do mobiliário. Esta condição acena a uma potencial construção de novos paradigmas. Além disso, a estrutura social contemporânea está totalmente modificada, e é cada vez mais difícil definir uma casaideal ou objeto-ideal, dada a existência de uma grande diversidade de grupos e de indivíduos.

Nóbrega (2011) nos fala dos há_bit(at) e dos há_bit(antes), edificações cíbridas ${ }^{8}$ e seus habitantes respectivamente. Coloca-nos discussões acerca dos novos códigos estético-simbólicos da residência e de seus moradores. O autor discute privacidade, fechamento, imobilidade, tão presentes nos conceitos fundadores de lar, contrapondo-os aos conceitos de virtual, rizoma e mobilidade junto à atualidade da cibercultura. Troca o conceito de família nuclear pelo de matilha, um todo coletivo e móvel.

Moura e Ricceti (2010), acerca do lar do futuro, propõem três agentes transformadores que podem provocar modificações na conformação da casa. $O$ primeiro são as inovações tecnológicas presentes no dia-a-dia das pessoas, em que a miniaturização, os aparelhos em rede e sem fio caracterizam os objetos; o segundo diz

\footnotetext{
${ }^{7}$ Um todo organizado e complexo; mecanismo aberto que ajusta múltiplas combinações e manifestações formais como um rizoma.

${ }^{8}$ Edificações cíbridas, segundo o autor, "são aquelas que possuem modos poéticos de hibridização da casa, ente material, com o ciberespaço, ente virtual, visando com essa simbiose construir um espaço cíbrido para morar na arte".
} 
respeito ao desenvolvimento sustentável que deve mudar hábitos e valores e substituir a quantidade pela qualidade; e por último o novo modo de comportamento do indivíduo e das estruturas familiares, que estão modificando as composições e os arranjos físicos do lar, como ilustra a figura 3.

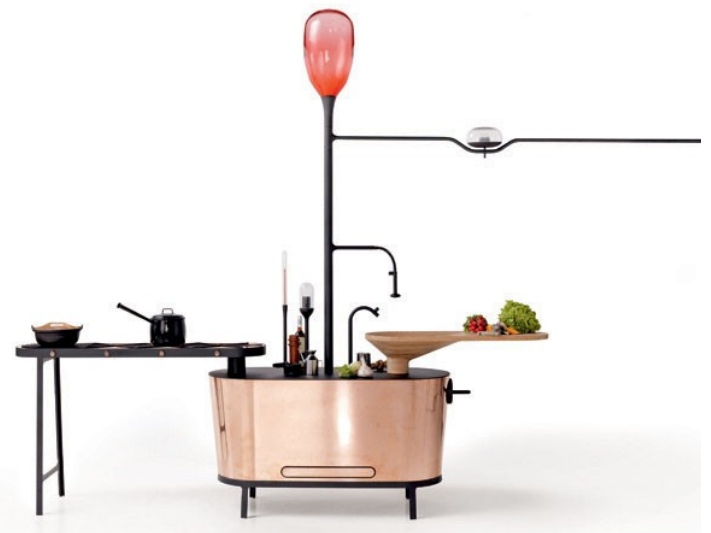

Figura 3 - Cozinha Microbial Home (2011), da Philips, que transforma resíduos domésticos em gás metano, usado como energia

Fonte: http://portalpitanga.com.br/gastronomia/a-cozinha-do-futuro-by-phillips/

Faz-se então a necessidade de encarar a casa, o modo de morar e as relações entre sujeito e objeto de outra forma.

Atualmente, Bauman (2007) usa os termos "líquida", "fluida" ou "inconstante" para descrever a sociedade atual. As conexões clássicas entre o indivíduo e o coletivo dissiparam-se; já não é mais necessário permanecer num lugar fixo, pelo menos de forma imóvel. A natureza do indivíduo atual é "líquida", "híbrida", já não pertence a um lugar, mas a um tempo "líquido". E nessa fluidez, liquidez, e inconstância as suas energias são empregadas em recuperar e conservar a sua individualidade.

\section{CONCLUSÃO}

A habitação do indivíduo contemporâneo há de ser, portanto, adaptável, e que possibilite troca e usos múltiplos, ou flexíveis. Este espaço pode transformar-se igualmente com os seus habitantes e ter vida própria, converter-se no reflexo constante de identidades, ser a materialização de um espaço vital, extensão da existência. Nele, quem estabelece e quem comanda é o indivíduo e suas necessidades.

Os móveis - aquele cofre, móvel primeiro, com suas relíquias -, que neles ora sobressaíam funções de uso, ora funções estéticas e simbólicas, guardam segredos e propõem relações, criam e recriam realidades. Pertencem à esfera entre o público e o íntimo. São aqueles pelos quais os sujeitos falam de si próprios, de suas memórias, de seus desejos, sonhos, medos, e valores.

Como participante ativo da condição de morar, o móvel se circunscreveu na formação do lar, da casa, e do cotidiano, e como objeto com fortes características simbólicas, podemos afirmar que cada móvel "vale pelo significado que the atribui quem dele tem necessidade e por ele desejo, e a relação já não é normativa, como se o objeto levasse em si instruções para o seu uso, mas também empatia e simpatia" (ARGAN, 1992b, p. 257). 


\section{REFERÊNCIAS}

ARGAN, G. C. Arte Moderna. São Paulo: Companhia das Letras, 1992a.

. História da arte como história da cidade. Rio de Janeiro: Martins Fontes, 1992b.

BAUMAN, Z. Tempos líquidos. Rio de Janeiro: Jorge Zahar Editor, 2007.

BAYEUX, G. $O$ móvel da casa brasileira. São Paulo: Ed. Museu da Casa Brasileira, 1997.

BENJAMIN, W. Louis-Philippe or the Interior. In: Charles Baudelaire: a lyric poet in the era of high capitalism. London: NLB, 1973. . Experiência e pobreza. In: . Obras escolhidas 1: magia e técnica, arte e política. São Paulo: Editora Brasiliense, 1994.

BOMFIM, G. A. Idéias e formas na história do design. João Pessoa: Editora Universitária, 1998.

BOYLE, C. (Ed.). $O$ mundo doméstico. Rio de Janeiro: Abril Livros, 1993.

FORTY, A. Objetos de desejo. São Paulo: Cosac Naify, 2007.

KATINSKY, J. R. As cinco raízes formais do desenho industrial. In: LEITE, J. S. et al. Arcos: design, cultura material e visualidade. Rio de Janeiro: Contra Capa, 1999.

MOURA, G.; RICCETTI, T. M. O lar do futuro. In: $9^{\circ}$ CONGRESSO BRASILEIRO DE PESQUISA E DESENVOLVIMENTO EM DESIGN, 2010. Anais.. São Paulo: Universidade Anhembi Morumbi, 2010.

NÓBREGA, C. M. da. Há_bit: tratado superficial de arquitetura cíbrida. 2011. Tese (Doutorado em Artes) - Universidade de Brasília, Programa de Pós-Graduação em Artes.

PERROT, M. (Org.). História da vida privada, 4: da revolução francesa à primeira guerra. São Paulo: Companhia das Letras, 2009.

PEVSNER, N. Os pioneiros do desenho moderno. São Paulo: Martins Fontes, 1994.

RYBCZYNSKI, W. Casa: pequena história de uma idéia. Rio de Janeiro: Ed. Record, 1999. 